\title{
The metabolic syndrome of fructose-fed rats: Effects of long-chain polyunsaturated $\omega 3$ and $\omega 6$ fatty acids. VII. Oxidative stress
}

\author{
ZOHEIR MELLOUK ${ }^{1}$, ABDULLAH SENER ${ }^{2}$, DALILA AIT YAHIA $^{1}$ and WILLY J. MALAISSE ${ }^{2}$ \\ ${ }^{1}$ Department of Biology, Es-Sénia University, Es-Sénia 31100, Oran, Algeria; \\ ${ }^{2}$ Laboratory of Experimental Hormonology, Université Libre de Bruxelles, B-1070 Brussels, Belgium
}

Received June 1, 2012; Accepted September 17, 2012

DOI: $10.3892 / \mathrm{mmr} .2012 .1093$

\begin{abstract}
In the present study, the plasma concentration, and liver, heart, kidney, soleus muscle and visceral adipose tissue content of thiobarbituric acid reactive substrates (TBARS), carbonyl radicals, hydroperoxides and nitric oxide were measured in control rats exposed for 8 weeks to a diet containing $64 \%$ (w/w) starch and 5\% sunflower oil and in animals fed a diet containing $64 \%$ D-fructose and $5 \%$ sunflower oil or $3.4 \%$ sunflower oil mixed with $1.6 \%$ safflower or salmon oil. Coherent measurements of the plasma concentrations or tissue contents of these metabolites revealed increases in TBARS, carbonyl radical and hydroperoxide levels and a decrease in nitric oxide levels in the $5 \%$ sunflower oil-fed rats. In the fructose-fed rats, the partial substitution of sunflower oil by either safflower or salmon oil minimized the changes. These findings provide further evidence in support of the favorable effects of the dietary supply of long-chain polyunsaturated $\omega 6$ and $\omega 3$ fatty acids upon the metabolic disturbances prevailing in the fructose-induced metabolic syndrome.
\end{abstract}

\section{Introduction}

In the preceding article in this series (1), attention was drawn to the activity of glutathione reductase, superoxide dismutase and catalase in the liver, heart, kidney, soleus muscle and visceral adipose tissue of control female rats exposed from the eighth week after birth and for the ensuing 8 weeks to a diet containing 64\% (w/w) starch and 5\% (w/w) sunflower oil (Ssun rats) and female rats exposed over the same period to diets containing 64\% D-fructose and 5\% sunflower oil (Fsun rats) or $3.4 \%$ sunflower oil mixed with $1.6 \%$ salmon oil (Fsal rats) or safflower oil (Fsaf rats). The activities of these enzymes were lower in the Fsun rats than in the Ssun rats; these decreases

Correspondence to: Professor Willy J. Malaisse, Laboratory of Experimental Hormonology, Université Libre de Bruxelles, 808 Route de Lennik, B-1070 Brussels, Belgium

E-mail: malaisse@ulb.ac.be

Key words: metabolic syndrome, fructose-fed rats, long-chain polyunsaturated $\omega 3$ and $\omega 6$ fatty acids were attenuated in the Fsaf and Fsal rats, particularly in the latter. In the light of such findings, the aim of the present study was to measure in plasma, liver, heart, kidney, soleus muscle and visceral adipose tissue the concentrations of thiobarbituric acid reactive substances (TBARS), carbonyl radicals, hydroperoxides and nitric oxide.

\section{Materials and methods}

The four groups of rats (Ssun, Fsun, Fsal and Fsaf) examined in the present study were the same as those mentioned in the preceding article in this series (1).

The measurements of TBARS were performed according to the methods of Salih et al (2) and Bostoglou et al (3), as adapted by Genot (4). The results are expressed as $\mu \mathrm{mol}$ of malonaldehyde equivalent (5). The plasma and tissue carbonyl content was measured according to the method of Levine et al (6), the results being expressed as $\mu$ mol per liter plasma or per $\mathrm{mg}$ tissue protein. The hydroperoxides were measured by the method proposed by Hermes-Lima et al (7), as modified by Eymard and Genot (8) and using the FOX 2 reagent (9). The results are again expressed as $\mu \mathrm{mol}$ by reference to cumene hydroperoxide standards (Sigma Aldrich, St. Louis, MO, USA). Finally, nitric oxide was measured by the method of Cortas and Wakid (10), the results being also expressed as $\mu \mathrm{mol}$.

All results are presented as mean values ( \pm SEM) together with the number of individual observations (n) or degree of freedom (df). The statistical significance of differences between mean values was assessed by use of the Student's $\mathrm{t}$-test. $\mathrm{P}<0.05$ was considered to indicate a statistically significant result.

\section{Results}

TBARS. The plasma concentration and tissue content of TBARS were invariably higher in the Fsun rats than in the Ssun rats (Table I). In the fructose-fed rats, the partial substitution of sunflower oil by either safflower or salmon oil opposed such an increase. Thus, relative to the corresponding reference values found in the plasma, liver, heart, kidney, soleus muscle and visceral adipose tissue of the Ssun rats $(100.0 \pm 5.5 \%$; $\mathrm{n}=36$ ), the measurements made in Fsun, Fsaf and Fsal rats averaged, respectively, $312.5 \pm 15.7(n=36), 214.2 \pm 13.2 \quad(n=36)$ and $177.6 \pm 11.7 \%(n=30)$, all four mean percentages being 
Table I. Plasma concentration $(\mu \mathrm{M})$ and tissue content $(\mu \mathrm{mol} / \mathrm{g}$ protein) of thiobarbituric acid reactive substances.

\begin{tabular}{lrrrr}
\hline & Ssun $(\mathrm{n}=6)$ & Fsun $(\mathrm{n}=6)$ & Fsal $(\mathrm{n}=5)$ & Fsaf $(\mathrm{n}=6)$ \\
\hline Plasma & $24.2 \pm 0.9$ & $80.1 \pm 0.7$ & $45.0 \pm 1.1$ & $53.5 \pm 1.2$ \\
Liver & $1.5 \pm 0.2$ & $5.3 \pm 0.7$ & $2.9 \pm 0.6$ & $3.4 \pm 0.4$ \\
Heart & $1.7 \pm 0.3$ & $2.7 \pm 0.1$ & $2.3 \pm 0.2$ & $2.6 \pm 0.2$ \\
Kidney & $1.4 \pm 0.2$ & $4.7 \pm 0.4$ & $3.2 \pm 0.6$ & $4.0 \pm 0.8$ \\
Soleus muscle & $1.5 \pm 0.2$ & $4.7 \pm 0.4$ & $2.4 \pm 0.4$ & $2.8 \pm 0.4$ \\
Visceral adipose tissue & $0.3 \pm 0.1$ & $1.1 \pm 0.1$ & $0.5 \pm 0.1$ & $0.6 \pm 0.1$ \\
\hline
\end{tabular}

Table II. Plasma concentration $(\mu \mathrm{M})$ and tissue content $(\mu \mathrm{mol} / \mathrm{mg}$ protein) of carbonyl radicals.

\begin{tabular}{lrrrr}
\hline & Ssun $(\mathrm{n}=6)$ & Fsun $(\mathrm{n}=6)$ & Fsal $(\mathrm{n}=5)$ & Fsaf $(\mathrm{n}=6)$ \\
\hline Plasma & $27.09 \pm 2.17$ & $37.09 \pm 0.69$ & $32.50 \pm 2.48$ & $34.18 \pm 1.73$ \\
Liver & $3.27 \pm 0.07$ & $4.16 \pm 0.06$ & $3.45 \pm 0.09$ & $3.56 \pm 0.06$ \\
Heart & $3.13 \pm 0.20$ & $4.34 \pm 0.19$ & $3.42 \pm 0.29$ & $3.55 \pm 0.14$ \\
Kidney & $3.36 \pm 0.40$ & $5.46 \pm 0.60$ & $4.05 \pm 0.56$ & $5.03 \pm 0.70$ \\
Soleus muscle & $2.04 \pm 0.24$ & $3.03 \pm 0.29$ & $2.45 \pm 0.11$ & $2.70 \pm 0.17$ \\
Visceral adipose tissue & $1.16 \pm 0.14$ & $1.60 \pm 0.17$ & $1.23 \pm 0.13$ & $1.53 \pm 0.14$ \\
\hline
\end{tabular}

Table III. Plasma concentration $(\mu \mathrm{M})$ and tissue content ( $\mu \mathrm{mol} / \mathrm{mg}$ protein) of hydroperoxides.

\begin{tabular}{lcrrr}
\hline & Ssun & Fsun & Fsal & Fsaf \\
\hline Plasma & $34.77 \pm 0.82^{\mathrm{a}}$ & $53.26 \pm 2.47^{\mathrm{a}}$ & $41.38 \pm 0.56^{\mathrm{b}}$ & $45.54 \pm 1.40^{\mathrm{a}}$ \\
Liver & $2.74 \pm 0.15^{\mathrm{a}}$ & $5.70 \pm 0.71^{\mathrm{a}}$ & $3.25 \pm 0.34^{\mathrm{b}}$ & $3.75 \pm 0.41^{\mathrm{a}}$ \\
Heart & $1.94 \pm 0.38^{\mathrm{b}}$ & $3.56 \pm 0.21^{\mathrm{a}}$ & $2.82 \pm 0.25^{\mathrm{b}}$ & $3.37 \pm 0.36^{\mathrm{b}}$ \\
Kidney & $4.86 \pm 0.50^{\mathrm{a}}$ & $8.58 \pm 1.06^{\mathrm{a}}$ & $5.36 \pm 0.88^{\mathrm{b}}$ & $5.56 \pm 0.86^{\mathrm{a}}$ \\
Soleus muscle & $3.90 \pm 0.07^{\mathrm{a}}$ & $6.48 \pm 0.10^{\mathrm{a}}$ & $4.42 \pm 0.17^{\mathrm{b}}$ & $4.55 \pm 0.06^{\mathrm{a}}$ \\
Visceral adipose tissue & $3.52 \pm 0.53^{\mathrm{a}}$ & $5.37 \pm 0.42^{\mathrm{a}}$ & $3.72 \pm 1.14^{\mathrm{b}}$ & $3.99 \pm 0.97^{\mathrm{a}}$ \\
\hline
\end{tabular}

${ }^{\mathrm{a}} \mathrm{n}=6 ;{ }^{\mathrm{b}} \mathrm{n}=5$.

significantly different $(\mathrm{P}<0.05$ or less) from one another. The results recorded in the Fsal rats represented $84.0 \pm 4.6 \%(n=30$; $\mathrm{P}<0.02)$ of those recorded in the Fsaf rats $(100.0 \pm 4.7 \% ; \mathrm{n}=36)$.

Carbonyl radicals. A situation comparable to that described for TBARS prevailed in the case of carbonyl radicals (Table II). For instance, in the plasma, the mean concentrations of carbonyl radicals displayed a Ssun $<$ Fsal $<$ Fsaf < Fsun hierarchy. Likewise, in the liver, heart, kidney, soleus muscle and visceral adipose tissue, the carbonyl content, expressed relative to the corresponding values found in Ssun rats $(100.0 \pm 4.0 \% ; n=30)$ averaged $143.0 \pm 5.6(n=30), 127.2 \pm 5.5(n=30)$ and $112.3 \pm 4.4 \%$ $(n=20)$ in the Fsun, Fsaf and Fsal rats, respectively. These four mean values were close to being significantly different from one another $(\mathrm{P}<0.06$ or less) and became so when the two sets of individual data to be compared were expressed relative to one another. For instance, in the latter procedure, the difference between Fsun and Fsaf rats yielded a P-value $<0.025$, as distinct from a P-value $<0.06$ when comparing the data normalized relative to the Ssun reference measurements.

Hydroperoxides. The results concerning the hydroperoxide content of the samples yielded similar information to that found in the TBARS measurements (Table III). Thus, in all cases (plasma, liver, heart, kidney, soleus muscle and visceral adipose tissue) the mean values always followed the same hierarchy, that is, Ssun $<$ Fsal $<$ Fsaf $<$ Fsun. The close analogy between the results collected in liver, heart, kidney, soleus muscle and visceral adipose tissue in terms of the diet-induced changes of TBARS, carbonyl and hydroperoxide content is shown in Fig. 1.

Nitric oxide. The measurements of nitric oxide yielded results vastly different from those so far considered, in one major 
Table IV. Plasma concentration $(\mu \mathrm{M})$ and tissue content $(\mu \mathrm{mol} / \mathrm{mg}$ protein) of nitric oxide.

\begin{tabular}{|c|c|c|c|c|}
\hline Rats & Ssun $(n=6)$ & Fsun $(n=6)$ & Fsal $(n=5)$ & Fsaf $(n=6)$ \\
\hline Plasma & $22.17 \pm 0.69$ & $11.84 \pm 0.16$ & $18.37 \pm 0.64$ & $16.66 \pm 0.68$ \\
\hline Liver & $3.20 \pm 0.37$ & $1.99 \pm 0.06$ & $3.46 \pm 0.10$ & $2.47 \pm 0.19$ \\
\hline Heart & $2.98 \pm 0.09$ & $2.11 \pm 0.12$ & $3.17 \pm 0.10$ & $2.27 \pm 0.16$ \\
\hline Kidney & $2.70 \pm 0.05$ & $1.67 \pm 0.12$ & $2.42 \pm 0.14$ & $2.07 \pm 0.06$ \\
\hline Soleus muscle & $1.84 \pm 0.25$ & $3.03 \pm 0.34$ & $2.61 \pm 0.43$ & $2.69 \pm 0.35$ \\
\hline Visceral adipose tissue & $1.41 \pm 0.09$ & $0.69 \pm 0.07$ & $1.27 \pm 0.11$ & $0.86 \pm 0.07$ \\
\hline
\end{tabular}

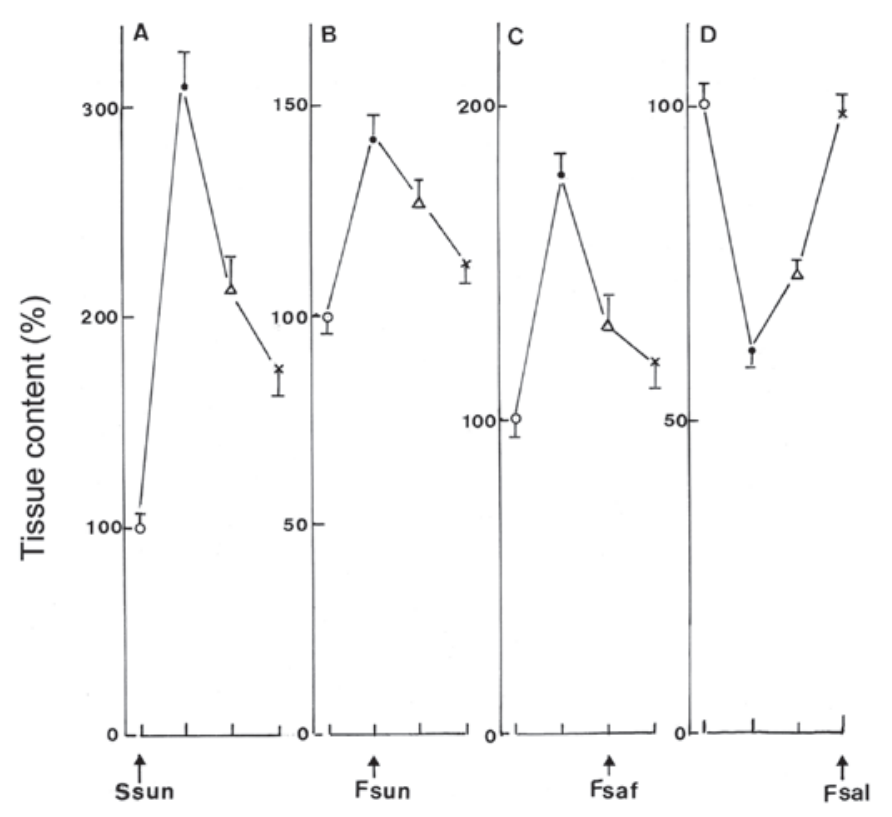

Figure 1. Comparison between Ssun (O), Fsun $(\bullet)$, Fsaf $(\triangle)$ and Fsal (x) rats in terms of tissue content of thiobarbituric acid reactive substrates (TBARS), carbonyl radicals, hydroperoxides and nitric oxide. Tissue content of (A) TBARS, (B) carbonyl radicals, (C) hydroperoxides and (D) nitric oxide. The results refer to measurements made in liver, heart, kidney, soleus muscle and visceral adipose tissue, with the exception of nitric oxide in which case the measurements made in soleus muscle were ignored. Mean values ( \pm SEM) are expressed relative to the corresponding values found in Ssun rats and refer to either 25-30 individual measurements (TBARS, carbonyl radicals and hydroperoxides) or 20-24 individual measurements (nitric oxide).

respect (Table IV). In plasma, the nitric oxide concentration was twice as low $(\mathrm{P}<0.001)$ in the Fsun rats as that in the Ssun rats. However, in muscle, the nitric oxide content was higher $(\mathrm{P}<0.02)$ in the Fsun rats than in the Ssun rats. The nitric oxide contents of liver, heart, kidney and visceral adipose tissue were lower in the Fsun rats than in the Ssun rats, the former averaging $60.9 \pm 2.5 \%(\mathrm{n}=24 ; \mathrm{P}<0.001)$ of the mean corresponding reference value in the latter $(100.0 \pm 3.2 \% ; \mathrm{n}=24)$. The relative magnitude of such a decrease $(39.1 \pm 4.0 \%$; $\mathrm{df}=46)$ was not significantly different $(\mathrm{P}>0.39)$ from that found in the plasma of the same rats $(46.6 \pm 3.2 \%$; $\mathrm{df}=10)$.

In analogy, however, with the results recorded for the other variables (TBARS, carbonyl and hydroperoxides), the partial substitution of sunflower oil by either safflower or salmon oil tended, in the fructose-fed rats, to minimize the difference otherwise found between Ssun and Fsun rats in terms of the nitric oxide content of plasma, liver, heart, kidney, soleus muscle and visceral adipose tissue. Relative to this difference $(100.0 \pm 5.5 \% ; n=36)$, that found in the Fsaf rats only represented $67.4 \pm 6.4 \%(n=36 ; \mathrm{P}<0.001)$, whilst in the Fsal rats such a difference was either further decreased $(\mathrm{P}<0.02)$ to $37.0 \pm 10.4 \%(\mathrm{n}=20)$ in plasma, kidney, soleus muscle and visceral adipose tissue or inverted in algebraic terms with an increment of $21.7 \pm 6.7 \%(\mathrm{n}=10 ; \mathrm{P}<0.02)$ instead of a decrement of $100.0 \pm 7.0 \%(n=12)$ when the respective differences between either Fsal or Fsun and Ssun rats in liver and heart were compared. The absolute values of the nitric oxide content of liver, heart, kidney, soleus muscle and visceral adipose tissue in the Fsal rats averaged 107.2 $\pm 6.1 \%$ $(n=25 ; P>0.29)$ of the corresponding values found in the Ssun rats $(100.0 \pm 3.6 \% ; n=30)$.

Fig. 1 shows the inverse situation found for the nitric oxide tissue content, on one hand, and the TBARS, carbonyl or hydroperoxide tissue content, on the other. For reasons already mentioned, the soleus muscle data for nitric oxide content were omitted from these computations.

\section{Discussion}

The measurements made in plasma were generally in fair agreement with those recorded in the organs considered in the present study. The data collected in liver, heart, kidney, soleus muscle and visceral adipose tissue provided coherent results, with the sole exception of the nitric oxide content of soleus muscle.

The main findings of the present study are shown in Fig. 1. It illustrates the fructose-induced increases in the tissue content of TBARS, carbonyl radicals and hydroperoxides and the fructose-induced decrease in the tissue content of nitric oxide. Furthermore, the fructose-induced changes were reduced in the Fsaf rats and reduced even further in the Fsal rats. In the latter, the mean values, on occasion, did not differ significantly from those found in the Ssun rats.

The accumulation of TBARS, carbonyl radicals and hydroperoxides in the liver, heart, kidney, soleus muscle and visceral adipose tissue of fructose-fed rats coincided with a decreased activity of the enzymes glutathione reductase, superoxide dismutase and catalase in the same organs of the same rats (1). Likewise, the response to the incorporation of either safflower or salmon oil in the diet in terms of the tissue content of TBARS, carbonyl radicals and hydroperoxides coincided with the partial correction of the fructose-induced changes in the activities of these enzymes. 
The potential benefit of the latter dietary manipulations, for example, in terms of either glucose homeostasis or prevention of arterial hypertension in human subjects, merit further consideration, as recently reviewed (11).

\section{Acknowledgements}

We are grateful to C. Demesmaeker for secretarial help.

\section{References}

1. Mellouk Z, Hupkens E, Antione M-H, Sener A, Ait Yahia D and Malaisse WJ: The metabolic syndrome of fructose-fed rats: effects of long-chain polyunsaturated $\omega 3$ and $\omega 6$ fatty acids VI. Further post-mortem investigations. Mol Med Reports (In Press).

2. Salih AM, Smith DM, Price JF and Dawson LE: Modified extraction 2-thiobarbituric acid method for measuring lipid oxidation in poutry. Poult Sci 66: 1483-1488, 1987.

3. Bostoglou NA,Fletouris DJ,Papageorgiou GE, Vassilopoulos VN, Mantis AJ and Trakatellis AG: Rapid sensitive and specific thiobarbituric acid method for measuring lipid peroxidation in animal tissue, food and feedstuff samples. J Agric Food Chem 42: 1931-1937, 1994.
4. Genot C: Some factors influencing TBA test. Report Diet-ox project (AIRIII-CT-92-1577), 1996.

5. Buedge JA and Aust SD: Microsomal lipid oxidation. In Biomembranes (Part C: Biological Oxidation) Methods in Enzymology. Vol 52. Fleisher SF and Packer L (eds.) London Academic Press, pp302-309, 1978.

6. Levine RL, Garland D, Oliver CN, Amici A, Climent I, Lenz AG, Ahn BW, Shaltiel S and Stadtman ER: Determination of carbonyl content in oxidatively modified proteins. Methods Enzymol 186: 464-478, 1990.

7. Hermes-Lima M, Willmore WG and Storey KB: Quantification of lipid peorixdation in tissue extracts based on Fe(III) xylenol orange complex formation. Free Radic Biol Med 19: 271-280, 1995.

8. Eymard S and Genot C: A modified xylenol orange method to evaluate formation of lipid hydroperoxides during storage and processing of small pelagic fish. Eur J Lipid Sci Tech 105: 497-501, 2003.

9. Wolff SP: Ferrous ion oxidation in presence of ferric ion indicator xylenol orange for measurement of hydroperoxides. Methods Enzymol 233: 182-189, 1994

10. Cortas NK and Wakid NW: Determination of inorganic nitrate serum and uring by kinetic cadmium-reduction method. Clin Chem 36: 1440-1443, 1990 .

11. Boukortt FO, Madrani Z, Mellouk Z, Louchami K, Sener A and Ait Yahia D: Nutritional factors and fructose-induced metabolic syndrome. Metab Funct Res Diab 4: 18-34, 2011. 